\title{
Analysis of Carbon Emissions and Productivity of China's Construction Industry Based on Panel Data
}

\author{
Dong Zhai ${ }^{1, a}$, Yajun Pang ${ }^{1, b^{*}}$ and Jiayi Wen ${ }^{2, c}$ \\ ${ }^{1}$ Institute of Civil Engineering Management, Zhejiang University of China \\ ${ }^{2}$ Institute of Geotechnical Research Management, Zhejiang University of China \\ azhaidong@zju.edu.cn, b13735504698@163.com, ${ }^{\mathrm{c}} 21612181 @ z j u . e d u . c n$
}

*The corresponding author

Keywords: Construction; Carbon emissions; Productivity; Panel data; Regional differences

\begin{abstract}
The paper analyzes the panel data of construction productivity, energy intensity effect of construction industry, energy structure effect of construction industry, R \& D intensity, foreign capital ratio and capital intensity as explanatory variables to obtain the carbon emission factors of construction industry in eastern, central and western parts of China. The impact of energy intensity and structural effects on carbon emissions are larger, the capital intensity of the central and western regions of the emission reduction effect is relatively obvious, while the foreign capital ratio and $\mathrm{R}$ \& D intensity for the regional construction industry Carbon emissions were not obvious, China's construction industry carbon emission factors in different regions and provinces vary, the construction industry productivity on the central and western carbon emissions of the positive effect is higher than the eastern provinces. Grasping these Regional differences is conducive to the healthy development of effective productivity in the construction industry, and control the overall carbon emissions of the construction industry to achieve national energy saving.
\end{abstract}

\section{Introduction}

China is currently the world's largest carbon emitter, its carbon emissions accounted for $27.7 \%$ of total global carbon emissions, per capita carbon emissions up to 7.2 tons, is the world's per capita carbon emissions 1.44 times[1]. At the same time, in recent years, the concentration of large-scale air pollution, but also for China's carbon emissions sounded the alarm[2]. As an important industrial sector, construction industry is the basic leading industry for the development of various industries. But at the same time, as a representative of high energy consumption and high pollution industries, the construction industry is also an important source of carbon emissions in China. According to the Intergovernmental Panel on Climate Change (IPCC) Fourth Assessment report, the construction industry consumes $40 \%$ of the global energy, and carbon emissions as high as $36 \%$ [3].

China's urbanization process is still rapid at this stage, an annual increase of about 15 to 2 billion square meters of new buildings, coupled with the energy consumption of the original building, the construction industry's carbon emissions situation is not optimistic. One important reason is that the current productivity of China's construction industry is still at a low level.

\section{Literature Review}

Most of the literature on foreign studies is based on macro-perspective, the focus of the study is the relationship between socio-economic development and carbon emissions. Holtz and Seldon (1995) and Selden and Song (1994) use panel regression models with random effects or fixed effects for empirical analysis [4,5].Holtz-Eakin and Selden (1995) analyze the CO2 emissions of the countries of the world and the panel data of the per capita income of the localities to find that the marginal consumption of $\mathrm{CO} 2$ decreases with economic growth[4]. Adolf (2010) conducted a study of energy consumption and carbon emissions from Ireland's construction industry through the input-output method. The results show that about three-quarters of carbon emissions are caused by local construction activities [6]. Slawomir Smiech, Monika Papiez (2014) used the Granger 
causality panel data to make assumptions about energy consumption and economic development in EU countries and found the correlation and correlation between energy consumption and economic development [7].

The related research in China focuses on the factor analysis of construction industry or economic development, and studies the relationship between carbon emissions from the upstream and downstream industries of the construction industry. Ji Jian-yue (2012) used the scenario analysis to calculate the marginal relationship between the consumption of building industry output value and construction carbon emissions, which shows that the energy consumption per unit output value of the construction industry is linearly related to the construction carbon emissions[8]. Wang Yi (2013) Based on our country from 1996 to 2010, the calculation of carbon emissions from the construction industry and China's GDP energy consumption in the production of gray correlation, and the overall relevance of more than 90\%[9]. Xie Shou-hong (2013) Based on the industry factorization method to analyze the impact of various industries on China's total carbon emissions, the contribution of carbon emissions to the construction industry is $73.35 \%$, of which the contribution rate of the construction industry is $11.33 \%$. The proportion of the construction industry is on the rise[10].

From the literature study, we can see that many domestic research is based on the secondary industry to discuss a number of industries, while ignoring the same industry belongs to the second sector of the construction industry. Therefore, the relationship between carbon emissions in the construction industry and the current development of the construction industry characterized by high productivity is significant.

\section{Methodology}

Variable Selection. This paper mainly chooses the construction industry productivity, the energy intensity effect of the construction industry, the energy structure effect of the construction industry, the R \& D intensity, the foreign capital ratio and the capital intensity to describe its impact on China's construction carbon emissions. The variables symbols are defined as follows.

C: Carbon emissions from the construction industry

P: Per capita annual value-added of construction industry

EI: Added value of energy consumption per unit of construction

ES: Energy consumption per unit of carbon emissions in the construction sector

RD: The proportion of the total output of special enterprises

CA: Foreign investment (Hong Kong and Macao) corporate assets as a percentage of total assets

IN: The ratio of investment in construction industry to total output value

Data Sources. The data of this paper span from 1999 to 2012, a total of 14 years. Because of the limited number of carbon emissions in the construction industry, we use the direct carbon emissions from the construction industry to express the carbon emissions from the construction industry in each province. The energy consumption of the construction industry is also converted to the standard of 10,000 tons through the IPCC coefficient through various energy consumption Coal said. The data comes from China Energy Statistical Yearbook (1999-2012). The number of employees in the construction industry comes from the China Economic Weekly (1999-2012). Other data are from the China Statistical Yearbook (1999-2012).

Build the Model. To reduce the heteroskedasticity, logarithmically change the explanatory and explanatory variables. Using the Cobb-Douglas production function model, the model is set as:

$$
L n C=\alpha+\alpha_{1} L n P+\alpha_{2} L n E I+\alpha_{3} L n E S+\alpha_{4} L n R D+\alpha_{5} L n C A+\alpha_{6} L n I N+e
$$

Panel analysis provides three basic models: the invariant coefficient model with no individual influence, the variable intercept model and the variable coefficient model. The invariant coefficient model assumes that the intercept term and the variable coefficient of the model are the same for each cross-sectional sample. If this model is established, there is no difference in carbon emissions in the construction industry in China. The variable of the variable model assumes that the coefficient For each cross-section sample is the same, but the cross-sectional sample of the intercept terms are not the same; variable coefficient model assumes that the slope of the model and intercept 
items for each cross-section sample is not the same, if this model is established, City of carbon emissions effect difference, should be a single calculation. In addition, Hausman test can be used to detect and select specific models.

Data Inspection. According to the data analysis of the original series, the carbon emission, productivity, energy structure intensity, R \& D intensity, foreign capital ratio and capital intensity of the construction industry are obtained as a stable series, and the other data can be obtained by the first order differential sequence. (E), construction energy structure effect (ES), R \& D intensity (RD), construction energy intensity effect (EI), energy intensity effect of construction industry (RD) ), Foreign capital ratio (CA) and capital intensity (IN) are first-order single-integer series, logarithm can eliminate the influence of unit root.

In order to prevent the cointegration between the series may exist, the need for Kao test, get the ADF P value of 0.0000 , less than 0.05 . Therefore, there is no cointegration relationship between the assumptions of the null hypothesis, that is, the existence of long-term stable equilibrium relationship among the series.

Determine the Model Type. For the whole country, the Hausman test has a P value of 0.1304 , and the variable coefficient model should be used to express the carbon emission function of each province. For the eastern, central and western regions, the $\mathrm{P}$ value is less than $10 \%$, so we accept the "fixed effect model" Assumptions.

The $F$ value of the national data $F$ is 1.0523 is less than F0.05 $(29,299)=1.68$, so we accept fixed effect model; and the eastern data F value of 3.8503 greater than F0.05 $(13,141)=2.23$, so we accept random effects model, For the central and western regions with the random effects model.

\section{Result}

Using the variable coefficient model, the regressions of the supply functions of the eastern provinces, the central provinces and cities, and the western provinces were carried out by using the random effect variable intercept model. The results are shown in Table 1.

Table 1 the impact of carbon emissions measurement results

\begin{tabular}{cccc} 
& \multicolumn{3}{c}{ Correlation coefficient } \\
\cline { 2 - 4 } variable & East area & Central Region & Western Region \\
\hline $\operatorname{Ln}(\mathrm{P})$ & $0.4576^{* * *}$ & $1.0766^{* * *}$ & $1.3140^{* * *}$ \\
$\mathrm{Ln}(\mathrm{EI})$ & $0.8769^{* * *}$ & $0.9153^{* * * *}$ & $0.8231^{* * *}$ \\
$\mathrm{Ln}(\mathrm{ES})$ & $0.5221^{* * *}$ & $0.7616^{* * * *}$ & $0.8523^{* * *}$ \\
$\operatorname{Ln}(\mathrm{RD})$ & $0.2511^{*}$ & $0.1081^{* * *}$ & $0.0008^{*}$ \\
$\operatorname{Ln}(\mathrm{CA})$ & $-0.1154^{* * *}$ & $-0.031^{*}$ & $-0.0113^{*}$ \\
$\operatorname{Ln}(\mathrm{IN})$ & $-0.1873^{* * *}$ & $-0.7681^{* * *}$ & $-0.8926^{* * *}$ \\
$\mathrm{R}^{2}$ & 0.9896 & 0.9959 & 0.9707 \\
Adjust $\mathrm{R}^{2}$ & 0.9871 & 0.9940 & 0.9620 \\
$\mathrm{~F}$ & 406.97 & 514.97 & 111.37 \\
$\mathrm{D}-\mathrm{W}$ & 1.7199 & 1.739 & 1.781 \\
\hline
\end{tabular}


* Indicates passing at a significance of $10 \%$, ** means passing at a significance of $5 \%$, *** means passing at a significant level of $1 \%$.

The effects of each factor in the three regions of east, middle and west on carbon emission were tested by significance test. The R2 value of the fitting degree was high, the ideal was significant and the degree of interpretation was high. According to the empirical results, it can be seen that the building productivity, energy intensity, energy structure and scientific research degree are positively correlated with carbon emissions in most provinces and eastern, central and western parts of the country, indicating that these factors have strong effects on carbon emissions Drive effect. The two independent variables of foreign capital ratio and capital density show negative correlation with carbon emissions of construction industry.

For the eastern provinces, the positive effects of carbon emissions on the energy intensity and energy structure effects of the largest, the impact of the impact of construction productivity compared to the Midwest is not particularly large observations. At the same time, the effect of foreign capital ratio on carbon emission reduction is more obvious than that of central and western regions, but the mitigation effect of foreign capital ratio and capital intensity on eastern construction industry is not strong.

For the central provinces, the construction industry productivity, energy intensity effect, the energy structure effect on the carbon emissions have a positive impact, R \& D intensity is not significant. At the same time, capital intensity for the construction industry, carbon emission reduction effect is obvious, but the foreign capital than the emission reduction effect is minimal.

For the western provinces, the largest positive impact of carbon emissions for the construction industry productivity, energy intensity and structural effects are still more obvious role, the same intensity of $\mathrm{R} \& \mathrm{D}$ impact is not high. In the emission reduction factor, the capital intensity still has a greater impact, the role of foreign capital than in the three parts of the minimum.

\section{Summary}

Through the analysis of the panel data, this paper obtains the effects of several factors on the carbon emissions of the construction industry in the eastern, central, western and provincial provinces of China. It is propitious to optimize the energy consumption of the construction industry by promoting the construction industry mode according to local conditions, and Raising the level of foreign capital in the construction industry, and increasing investment in research and development in the construction industry to achieve the healthy development of the construction industry on the basis of effective productivity and control the overall carbon emissions of the construction industry to achieve the national energy-saving emission reduction targets.

The main drawback of this research is that $\mathrm{R} \& \mathrm{D}$ investment in China is expressed by the proportion of the total output of special enterprises, which needs further study to select more reasonable data to refer to, to carry out a more comprehensive and systematic targeted supplement.

\section{References}

[1] J.J. Xun and X.Z. Zhao: China's low - carbon economic development report (Social Science Academic Press,China 2014)

[2] J.J. Xun and X.Z. Zhao: China's low - carbon economic development report (Social Science Academic Press, China 2013)

[3] S.J. Qi and Y.B. Zhang: Soft science, Vol. 27 (2013) No.6, p.39-43

[4] T.M. Selden: Journal of public economics, Vol. 57 (1995) No.1, p.85-101

[5] Grossman: National Bureau of Economic Research, Vol. 30 (1994) No.2, p61

[6] Acquaye and Duffy: Building and Environment, Vol. 45 (2010) No.3, p784-791

[7] Smiech and Papiez: Energy Policy, Vol. 71 (2014) No.1, p118-129 
[8] J.Y. Ji and X.K. Jiang: Journal of Ocean University of China, Vol. 25 (2012) No.1, p53-57

[9] Y. Wang: Journal of Shijiazhuang University of Economics, Vol. 36 (2013) No.3, p53-59

[10]S.H. Xie and X.Y. Xu: Resource Development and Market, Vol. 29 (2013) No.1, p28-31 